\title{
A HiSTÓRIA DE GRISELDA: \\ ENCRUZILHADA DE TRADUÇÃO LATINO-ROMANCE DURANTE O HUMANISMO
}

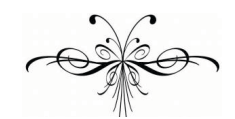

FRANCISCO JAVIER CALVO DEL OLMO

Resumo: Este trabalho apresenta a primeira tradução para o catalão, realizada por Bernat Metge, do conto de Griselda, centésima novela no Decameron de Boccaccio. Na primeira parte desenha-se o percurso da difusão do texto nas sucessivas traduções e nos âmbitos linguísticos e culturais que a fortuna dessa história vai progressivamente atingindo. Em seguida apresentamos, no original e em tradução ao português, a carta escrita pelo tradutor catalão à dama Isabela Guimerà, a quem dedica sua obra; nela o tradutor justifica o seu trabalho. Por último reproduzimos parte do conto no original toscano, na tradução latina - fonte na que se inspira Bernat Metge -, na tradução catalã, e nas traduções francesa, espanhola e portuguesa. Procuramos apresentar, assim, as semelhanças e diferenças entre o modelo toscano e as traduções latina e romances.

Palavras-chave: Decameron; Bernat Metge; tradução latino-romance.
Abstract: This essay presents the first translation into Catalan of the tale of Griselda, hundredth novella of Boccaccio's Decameron, carried out by Bernat Metge. In the first part we depict the diffusion paths of the text's successive translations and show the different linguistic and cultural contexts reached by Griselda's story. Then we present (both in the original and in a Portuguese translation) the letter written by the Catalan translator to Lady Isabella Guimerà, to whom the work is dedicated. Finally we reproduce part of the tale in the original Tuscan, in the Latin translation - Bernat Metge's direct source - and in the Catalan, French, Spanish and Portuguese translations. We thus show the similarities and differences between the Tuscan model and the Latin and Romance translations.

Keywords: Decameron; Bernat Metge; Latin-Romance translation. 


\section{A história de Griselda na Itália: original toscano de Boccaccio e a versão latina de Petrarca}

Ao escrever o Decameron - aproximadamente entre 1349 e 1351- Giovanni Boccaccio não só erigia um dos alicerces da prosa em língua vulgar toscana senão que oferecia uma obra-prima à literatura universal. Seguindo a tradição de mise en abyme, que já havia sido usada em coleções anteriores de contos, ocidentais e orientais, o escritor de Certaldo inscreveu as cem novelle em um marco narrativo, conformando assim uma sorte de romance ou, pelo menos, um mosaico de histórias. As novelas são narradas por um grupo de jovens que haviam fugido de Florença para se proteger da peste negra. Essa comunidade, formada por sete moças e três rapazes, organiza o seu lazer segundo as modas cortesãs, que incluem a narração de contos. O décimo dia é uma quarta-feira e, segundo as regras criadas pelos narradores, o rei é Panfilo. Os contos da última jornada têm como tema comum a virtude, seguindo assim uma parábola moral ascendente, conforme o esquema da poética medieval; tal recurso é similar ao que Dante havia usado na Divina Commedia, com a evolução Inferno, Purgatório, Paraíso. O jovem e controverso Dioneo é quem conta a centésima novella, dedicada à paciência que a humilde Griselda mostra em todo momento perante as provas às quais é submetida pelo seu marido, o marquês de Saluzzo, Gualtieri. No início do conto, os vassalos do marquês pedem-lhe que encontre uma esposa e assim ele escolhe a filha de um miserável aldeão, a gentil Griselda. Em seguida, a moça ganha elogios na corte pela sua gentileza e, algum tempo depois do casamento, dá uma filha ao marquês. Porém, o marido decide pôr à prova a paciência e as virtudes da sua esposa e, para isso, finge matar a criança; mas ela persiste imutável no seu amor. Anos depois Griselda dá à luz outro filho do marquês, dessa vez um menino; o marido não satisfeito da prova anterior volta a fingir matar o infante sem que por isso Griselda desista dos votos feitos no dia do casamento. Então Gualtieri decide expulsar a mulher de casa e a obriga a servir à própria filha - tida como morta por Griselda - com quem ele simula querer casar em segundas núpcias. Ela dá mostras, mais uma vez, da sua inesgotável paciência. Finalmente, convencido do amor e da virtude de Griselda, Gualtieri a devolve à sua posição de marquesa e faz os dois filhos voltarem para morar junto com eles.

Talvez devido à posição privilegiada que a história ocupa dentro do livro - lembremos que é a décima novela do décimo dia -, talvez por ser a mais nobre segundo a sua progressão ascendente, a Griselda é uma das historias do Decameron que maior difusão e sucesso alcançou, como veremos. Cabe dizer também que essa chave de ouro fecha uma estadia de quatorze dias (pois além dos dias dedicados às narrações, o autor nos informa que as sextas-feiras eram reservadas à oração e os sábados aos cuidados pessoais das moças) e marca a volta dos jovens a Florença, o que significa - como já apontou algum crítico - o provável caminho que conduz a morte, pois a cidade estava infestada pela doença.

Mas antes de entrar nas traduções dessa história, argumento central do presente trabalho, gostaríamos de dedicar um breve parágrafo para reconhecer o público alvo a quem Boccaccio dirigiu o Decameron. $\mathrm{O}$ autor declarou ter escrito esse livro para as mulheres que o leriam como entretenimento, e não para um público erudito. Assim, o escritor procura conquistar um leitor ou, melhor ainda, uma leitora, que pertence à classe burguesa, principalmente urbana. As mulheres da época, devido às regras sociais, não podiam participar de certos entretenimentos, como o jogo ou a caça, e passavam a maior parte do tempo confinadas no ambiente doméstico. Esse dado é tido como relevante na história da transmissão de Griselda, espe- 
cialmente na tradução catalã de Metge.

O grande humanista Petrarca, amigo de Boccaccio, decide verter ao latim a centésima novella vinte anos após a aparição do Decameron. E, assim, dá início à transmissão do conto. Provavelmente escolheu a Griselda seduzido por sua temática, que o aproxima das virtudes humanísticas e cristãs, e o afasta da temática laica e profana de outras novelle. Petrarca fez a tradução da Griselda já velho e doente, pouco antes de morrer. Consideramos isso um indicador da apreciação positiva que aquela novella pudera lhe inspirar. Ele não se debruça sobre o texto como faria um tradutor atual, tentando ficar o mais "fiel" ao original, mas empreende uma refundação da história, introduzindo notáveis diferenças com respeito ao seu modelo, que fica subordinado aos objetivos do próprio Petrarca, isto é, a elevação do conto linguística (pois passa da língua vulgar romance para a clássica latina) e estilisticamente (segundo as ideias estéticas e retóricas do humanista). Segundo Nardone e Lamarque (2000), os cortes e as adições que Petrarca faz dão como resultado final uma fábula diferente: já não se exaltam as virtudes das mulheres fieis, mas sim as do perfeito cristão que se mantém firme na sua fé perante as adversidades e as provas às quais é submetido. E, desse modo, a personagem de Griselda se transforma em uma sorte de Jó, piemontês e feminino. Conde (2001) aponta na mesma direção ao salientar três fatores da tarefa de Petrarca que resultaram fundamentais na difusão da mesma. Esses são: em primeiro lugar, ao verter o texto em latim deu à história um estilo elevado e uma dignidade artística maior; em segundo, a versão latina - língua de cultura dos humanistas - garantiu uma difusão entre o público culto universal, eficaz e sem mediadores; e, por último, a tarefa do Petrarca tradutor converteu a história em fábula alegórico-moral.

Quando Petrarca concluiu a reescrita de Griselda, enviou o texto em uma carta (Seniles XVII, 3\&4) a Boccaccio. No prólogo da tradução ele se desculpava pelas mudanças e explicava as suas intenções. Segundo Riquer (1959, pp. 45-48), aquela carta, enviada em abril de 1373 em forma de epístola avulsa, nunca chegou às mãos do seu destinatário. Sempre segundo o mesmo filólogo, em junho de 1374, um mês antes da sua morte, Petrarca enviou de novo a tradução; dessa vez havia introduzido algumas correções e mudanças no texto, incluindo o título - a primeira versão se chamava simplesmente Griseldis, enquanto a segunda levava um título mais elaborado: De insigni obedientia et fide uxoris. E, além disso, acompanhava a tradução um posfácio. A crítica moderna especializada em Petrarca inclui ambas as epístolas no Rerum senilium; a primeira constitui a epístola terceira do livro XVII e a segunda a quarta do mesmo livro.

Aqui consideramos que a tradução latina de Petrarca constitui um poderoso alicerce da difusão de Griselda e da sua descendência literária ${ }^{1}$. Como veremos a seguir, da versão latina de Petrarca (e não do original toscano, lembremos) realizaram-se várias traduçõesversões em várias línguas do âmbito românico e europeu em um brevíssimo lapso de tempo. Elas são a prova do sucesso que aquele texto teve. Isso fez com que a história de Griselda terminasse por se incorporar finalmente tanto aos registros folclóricos como aos literários cultos, e atingisse até os domínios de outras artes, como a pintu-

\footnotetext{
${ }^{1}$ A história de Griselda (...) teve uma enorme difusão em diferentes âmbitos literários de todo o mundo. Boa prova são, por exemplo, os denodados esforços de Raffaele Morabito, professor do Departamento de Culture Comparate dell'Università dell'Aquila, para formar um centro de estudos sobre o tema. O citado professor organizou dois Congressos: o primeiro, durante os dias 3 e 4 de dezembro de 1986, sobre La circulazione dei teme e degli intrecci narrative: il caso Griselda (atas publicadas por Jadraque Editore, dois anos depois); e o segundo, do 12 ao 14 de maio de 1988, sobre Modi dell'intertestualità: la storia di Griselda in Europa. (ROMERA CASTILLO: 2009, pp 210).
} 
ra e a iconografia.

\section{A história de Griselda na Catalunha: a tradução de Bernat Metge}

Bernat Metge (Barcelona, entre 1340 e 1346-1413) foi escritor, tradutor e atualmente é considerado como o primeiro representante do humanismo no âmbito cultural catalão. Seu pai era um farmacêutico chamado Guillem Metge que morreu quando Bernat era ainda uma criança. Sua mãe casou de novo, com Ferrer Sayol, que trabalhava como notário na Chancelaria Real, além de ser um apaixonado leitor dos clássicos e tradutor. Graças ao seu padrasto, o jovem Bernat pôde começar a trabalhar para o rei como escrivão, sob o comando do Primeiro Notário. Esses trabalhadores eram pessoas preparadas tecnicamente; deles exigia-se uma formação nas disciplinas da gramática, da retórica e da dialética, além de uma boa competência linguística porque as leis se escreviam em latim fazendo-se depois se duas versões: uma em aragonês e outra em catalão, sendo ambas as línguas oficiais do reino de Aragão. Assim, eles foram os primeiros a receber a influência, cultural - e linguística - do Humanismo. Essa formação fundamental se completava com uma série de modelos de correção linguística e estilística tomados não apenas de clássicos (como Ovídio) senão de intelectuais medievais, como Santo Agostinho ou Raimundo Lúlio.

A maior parte da vida de Bernat Metge ocorreu intimamente ligada aos reis de Aragão, primeiro ao rei Joan I o Caçador e mais tarde ao rei Martí. Enviado pelo rei Joan I, Bernat Metge passou alguns anos na cidade de Avinhão, onde então estava sediada a corte papal. Muito provavelmente foi lá onde o funcionário barcelonês se aproximou da obra de Petrarca. Como dizíamos, todas as ars dictaminis e os De regimine principis ou ciuitatum medievais para o uso de funcionários e governantes destacavam a importância da formação gramatical e retórica, e a corte papl de Avinhão havia elevado Petrarca como o melhor desses profissionais da palavra e da pluma. Enquanto homem de letras, Metge mostrou um espírito amplamente aberto às ideias coetâneas. Dentro da sua própria produção literária, cabe mencionar que o primeiro livro, Llibre de Fortuna e Prudència (1381), recebeu influências do francês Roman de la Rose. Nas suas obras mais celebradas podem rastrear-se igualmente influências de autores clássicos; o Sermó humorístic i paròdic está inspirado em De consolatione philosophiae de Boécio e Lo somni (1399), sem dúvida a sua obra-prima, comparte certos traços com a Divina Commedia de Dante devido ao seu caráter alegórico. Sabemos que Bernat Metge teve problemas com a justiça real sem que estejam claras quais foram as acusações nem quem os acusadores. Em todo caso, viu-se obrigado a pedir ajuda a uma antiga amiga: Isabel de Guimerà, que graças ao seu casamento com Gispert de Guimerà, senhor feudal de Ciutadella, em 1372, era uma pessoa influente na corte. Quando finalmente foi reconhecida sua inocência, em 1388, é reabilitado no seu cargo,Metge procurou uma história que pudesse agradar à sua benfeitora, dama burguesa e refinada, o mais nobre conto do Decameron apresentava-se como a escolha certa. Madona Isabel de Guimerà se enquadrava no público alvo de Boccaccio, e ambas, tanto o original toscano quanto a versão catalã, fazem parte de um mesmo contexto cultural, medieval e românico. A tradução que Metge fez da Griselda (que leva por título Història de Valter e Griselda) pode ser considerada como um ato de agradecimento ${ }^{2}$.

${ }^{2}$ O filólogo Martín de Riquer reconstruiu a transmissão do texto; o conto de Griselda se conserva em dois manuscritos: o Ms. U, da Biblioteca Universitária de Barcelona (fols. 128-35) e o Ms. B, na Biblioteca da Catalunha (fols.30-41). Além 
Ora, parece-nos destacável que Metge acompanhe a sua versão de duas cartas, uma a modo de prólogo e outra como epílogo, em clara mimese com as cartas que Petrarca escreveu para enquadrar sua tradução. Essa carta prólogo é considerada uma das primeiras referências dedicadas a Petrarca na Península Ibérica; ou seja, uma das primeiras testemunhas do petrarquismo ibérico. Só conhecemos uma referência mais antiga feita a Petrarca também no âmbito catalão: localiza-se em uma carta escrita em latim por Pere de Pont, que o chama de "laureatus poeta". A crítica já assinalou o parecido com o "poeta laureat" que Metge lhe atribui. Para Tavani (1979) isso é a prova de que as notícias circulavam amplamente entre os intelectuais catalães. Sem entrar em uma bibliografia pormenorizada de Metge, parece-nos interessante notar que uma das filhas do autor barcelonês recebeu o nome de Griselda, indício talvez da importância que aquele conto toscano atingiu na vida de Metge.

Esse "arromançamento"3 é a mais antiga das traduções de Boccaccio que se fariam, e que ainda hoje continuam se fazendo, na Península Ibérica. Ora, se nos detivermos a analisar o trabalho de Bernat Metge como tradutor, poderemos questionar se ele usou unicamente o relato em latim de Petrarca ou se, pelo contrário, tivera conhecimento do original em romance de Boccaccio. Na carta que serve como prólogo, lê-se "la Història de Valter e de la paciente Griselda, escrita en llatí per Francesch Petrarca, e arromençada por Bernat Metge"; do que se poderia deduzir que ele se baseou exclusivamente na narração latina. $\mathrm{E}$, de fato, a crítica considerou tra-

de estar integrado em uma tradução catalã da obra de Boccaccio de 1429 conservada também na Biblioteca da Catalunha (Ms. D, 1716, fols. 324v-30v) Muito tardiamente a tradução de Metge apareceria impressa em Barcelona por M. Aguiló y Fuster, publicada em 1883.

${ }^{3}$ Processo de tradução do latim a uma língua românica. (N. do Ed.) dicionalmente a tradução latina de Petrarca como fonte da versão catalã. Entretanto, estudos mais recentes demonstraram que o autor de Barcelona conheceu o texto original de Boccaccio em toscano. Martín de Riquer (1959) demostrou solidamente que a narração catalã traduz a latina das Seniles com maior fidelidade e que "Bernat Metge es mucho más fiel traduciendo a Petrarca que éste cuando traduce a Boccaccio" (p. 53). O escritor catalão sabia que o seu modelo não era um original, mas sim uma tradução de um conto do Decameron. O próprio Tavani (1979) fez uma comparação estrita dos textos e indicou que, ainda que o escritor catalão usasse essencialmente a redação latina, serviu-se também do original toscano. Segundo esse filólogo, as maiores divergências entre a tradução catalã e o texto latino das Seniles consistem basicamente em que Metge elimina uma parte das correções e dos acréscimos que Petrarca havia introduzido na narração de Boccaccio. O propósito do tradutor barcelonês seria, pois, o de potenciar a verossimilhança e a exemplaridade. $\mathrm{O}$ mesmo Tavani faz uma análise comparativa das divergências que ele encontra ao longo do corpo do texto. A primeira aparece no mesmo exórdio no qual Petrarca faz uma longa descrição do Piemonte, dos Alpes e do vale do rio Po; algo que tem um marcado carácter localista, que talvez pretendesse criar já desde o início um maior efeito realístico. Entretanto, Metge condensa o mesmo exórdio em uma rápida alusão à localização, ao marco onde vai acontecer a ação (veja-se o início do conto que reproduzimos no presente trabalho). Mais notável nos parece a diferença apresentada no discurso direto em que um dos súditos de Valter, em nome de todos, expressa a petição de que o marquês case: "ut coniugio scilicet animum applices, collumque non liberurn modo sed imperiosum legitimo subicias iugo". Boccaccio havia colocado esta petição em apenas uma frase em discurso indireto: "che moglie prendesse". Metge, por sua vez, escreve na tradução catalã em estilo direto "que vulles pendre muller". Assim 
se evidencia o parecido da expressão nos dois textos em romance, o de Boccaccioe o de Metge, e a diferença de ambos com a forma latina, dePetrarca .

Sem entrar a comentar todas as diferenças entre as versões latina e catalã, a autonomia do tradutor catalão se limita a eliminar do texto de Petrarca tudo aquilo que julga supérfluo ou até negativo para a economia narrativa; e a imitatio ${ }^{4}$ que faz seleciona os elementos que ajudam a produzir um texto literário na língua de chegada sem ficar atado a uma tradução au pied de la lettre. Esse é o resultado que o tradutor procura: criar um modelo de prosa artística no incipiente romance catalão, fornecendo modelos linguísticos, estilísticos e literários a esse idioma, e transpondo fórmulas e padrões do latim, língua que, como vimos, Metge também sabia escrever com elegância.

Todavia, parece necessário supor (como já concluiu Tavani, 1979) o conhecimento do original de Boccaccio por parte de Metge, pois, de outra maneira, resultaria bastante difícil explicar como o tradutor, ao se afastar do seu modelo principal latino, teria conseguido, por iniciativa própria, restaurar, no seu conjunto, ou em parte, esquemas narrativos do Decameron que Petrarca havia alterado. Entretanto , Tavani aporta uma hipótese alternativa para explicar a relação entre a tradução catalã e o original do Decameron: Bernat Metge poderia haver tido acesso à tradução francesa de Philippe de Mézières (feita em torno ao 1384). O escritor catalão trabalhava ao serviço do herdeiro à corona aragonesa (posteriormente coroado

\footnotetext{
${ }^{4}$ A imitatio é um conceito retórico e literário presente já na Roma antiga como tradução da voz grega mímesis ou mimese. A imitatio designa a faculdade de imitar, copiar, reproduzir ou refazer um modelo precedente. Segundo a filosofia aristotélica, a reprodução ou imitação dos modelos presentes na natureza é o fundamento de todas as artes.
}

como Joan I em 1387), que era casado com Violante, princesa da família ducal lorenesa, parentes próximos do rei de França. Assim, as novidades vindas do outro lado dos Pirineus não deviam ser de muito difícil acesso para o nosso autor. Desse modo, Metge haveria tomado a tradução de Mézières como fonte secundária na elaboração da sua. Em tal caso, vemos que, já seja a partir do conhecimento do original toscano ou através da tradução francesa (ou inclusive, porque não, das duas), Metge não usou exclusivamente o texto latino de Petrarca, mas provavelmente se apoiou em versões romances para realizar o seu trabalho.

O resultado final é um conto com autonomia linguística e estilística que gozou de uma notável difusão. Desse modo, na primeira tradução do Decameron para o catalão, aparecida em $1429^{5}$, o tradutor, ou os tradutores, ao chegar à última novella $(\mathrm{X}, 10) \mathrm{em} \mathrm{vez}$ de seguir vertendo o texto italiano, copiaram o Valter e Griselda de Bernat Metge, prescindindo das epístolas a Isabel de Guimerà e sem citar o nome do nosso escritor, logo que, em rigor, não era uma cópia destinada a transmitir o texto de Metge (Riquer, 1959). No século XVI, o valenciano Joan Timoneda também se serviria da versão catalã para realizar a tradução espanhola, como veremos a seguir.

\footnotetext{
${ }^{5}$ Cfr. BADIA (1973-1974) para um estudo da tradução catalã do Decameron de 1429.
} 


\section{A história de Griselda em outros âmbitos europeus: França, Es- panha e Portugal}

As numerosas traduções, reelaborações e ressonâncias do conto de Boccaccio são uma boa prova da difusão que a Griselda atingiu tanto dentro da Península Itálica como além das fronteiras alpinas. As cartas de Petrarca circularam de forma manuscrita durante o século XIV e posteriormente entraram nas primeiras imprensas alemãs e francesas; existe uma cópia impressa em Lyon, de aproximadamente 1485 , e outra em Toulouse em 1490. As cartas de Petrarca dirigidas a Boccaccio, junto com a tradução (XVII 3 \& 4), são publicadas como um texto avulso, independente da antologia epistolar que conforma as Seniles. A cronologia é a melhor testemunha da rápida difusão do texto; composto por Petrarca em 1373, a tradução de Bernat Metge para a nobre Isabel de Guimerà, no âmbito catalãoaragonês, data de 1388, enquanto a tradução francesa de Philippe de Mézières seria ainda anterior, de 1384, embora outros críticos forneçam uma data algo posterior: 1389.

Philippe de Mézières (1327-1405) pertenceu à pequena nobreza picarda, tendo sido um homem de armas e um místico que combateu nas Cruzadas, e que viajou várias vezes ao Oriente. Convencido da necessidade de criar uma nova ordem de cavalaria buscou a unidade dos reinos cristãos em uma luta efetiva contra os muçulmanos. Defendeu essas ideias veementemente perante reis e papas, com pouco sucesso. Aqui interessa-nos mais a figura de Philippe de Mézières como homem de letras e como tradutor do latim e de Petrarca.

Elle [la traduction française] peut être considérée comme une réaction quasi immédiate du pré-humanisme française et constitue, si on la met en rapport avec la multiplication des manuscrits, pourtant onéreux et exposés aux dangers du transport, un succès réel, qui ira en s'amplifant.
(Lamarque, 2000, pp 60)

Cabe dizer que a centésima novella do Decameron chamou a atenção de outros humanistas que também realizaram versões em latim, como Neri de' Nerli, Jacopo Filippo Foresti e até Leonardo Bruni. Entretanto, a versão de Petrarca foi, de todas, a que atingiu uma difusão maior, até chegar a eclipsar durante muito tempo o original escrito por Boccaccio. Uma nova versão, desta vez em inglês, é a que dá Chaucer no "The Clerk's Tale", inclusa nos Canterbury Tales, escrito também na década de 1380.

No particular exemplo da imitatio que nos ocupa neste trabalho, podemos estabelecer uma filiação na transmissão: em primeiro lugar colocamos o conto do Decameron escrito em romance toscano; em seguida vem a versão latina de Petrarca, que se difunde pelo arco mediterrâneo e chega à França, onde Philippe de Mézières o verte ao francês; em seguida, a Catalunha, onde é Bernat Metge que o traduz para o catalão. Em etapas sucessivas, o valenciano Joan Timoneda traduz do catalão para o castelhano, e o português Fernandes Trancoso traduz do espanhol para o português. El Patrañuelo de Timoneda aparece em 1567 como uma coleção de relatos breves inspirados formal e tematicamente nas novelle italianas. A segunda das 22 patrañas que o integram é uma versão da história da Griselda; chamada Grisélida. Vários foram os pareceres da crítica sobre a procedência dessa versão ${ }^{6}$. Desde Castilha, a história chega finalmente a Portugal, onde Gonçalo Fernandes Trancoso traduz o relato de Timoneda, quase ao pé da letra, no conto V da Terceira Parte de Contos e historias de Proveito e exemplo. Assim, a história de Griselda penetrou profundamente na cultura europeia no espaço de uns poucos anos, atravessando fronteiras políticas e linguísticas como

${ }^{6}$ Para um panorama das diversas considerações da crítica cf. ROMERA CASTILLO (1993). 
um jogo de espelhos e de repetições sucessivas em que a imagem vai se distorcendo progressivamente de forma inevitável:

La historia del rigor del atrabiliario marqués Gualtieri y de la paciencia de la abnegada e indoblegable Griselda va a atravesar fronteras, lenguas y épocas, para llegar a transformarse, desde su primitiva naturaleza de texto literario individual, en una suerte de leyenda, mito o símbolo al alcance de todo tipo de ingenios literarios, en un proceso de regresión o inversión retórica desde el texto finalizado hasta la reducción privilegiada al caudal de la inventio universal, retroceso que es garantía plena de la inmortalidad literaria. (Conde, 2001, pp 351)

Para terminar a rápida apresentação das traduções, versões, adaptações e paráfrases do conto de Boccaccio que fizemos nestas páginas, gostaríamos de remontar às fontes da transmissão de Griselda. O crítico Vittore Branca (1994) assinalou que o Decameron representa um compêndio das principais fontes literárias em circulação na época imediatamente anterior. Elas vão desde coleções de histórias da literatura grega e latina a compilações medievais, como o Livro dos sete sábios ${ }^{7}$, e o Novellino ${ }^{8}$, a contos dos mercantes florentinos, aos fabliaux ${ }^{9}$ franceses, a cantares dos menestréis e a exempla. Outros críticos, como Harkins (2008), pesquisaram as intertextualidades existentes entre a centésima história do Decameron e o conto de Eros e Psiquê que narra Apuleio nos livros IV e V do

\footnotetext{
${ }^{7}$ Os sete sábios de Grécia eram pensadores pré-socráticos aos que o próprio Sócrates se referiu para defender que a humildade é o caminho para a sabedoria. A tradição dos sete sábios de Grécia se manteve vigente durante toda a Antiguidade e atravessou o Medioevo.

${ }^{8}$ Il Novellino é uma coleção toscana de contos compilada afinais do século XIII a parir de fontes folclóricas e cultas e de tradições orientais e ocidentais.

${ }^{9}$ Os fabliaux são breves poemas narrativos franceses dos séculos XII e XIVcom um contido erótico ou humorístico e um marcado carácter popular.
}

Asno de Ouro ou As Metamorfoses ${ }^{10}$. Griselda revela-se, assim, exemplo excepcional da intertextualidade que permeia toda a história da literatura, pelo menos da tradição ocidental, através dos séculos.

\section{As cartas à madona Isabel de Guimerà}

A seguir reproduzimos as duas cartas originais em catalão medieval que Bernat Metge escreveu à destinatária da sua obra e, ao lado, a tradução em português proposta pelo autor deste artigo. A primeira carta precede à narração, propriamente dita, e serve assim como prólogo; a segunda aparece no final da narração e serve como epílogo. As duas cartas são apresentadas separadas apenas pelo sinal

\section{$\star \star \star$.}

A la molt honorable e honesta senyora madona Isabel de Guimerà, Bernat Metge, salut e reverència subjectiva.

A mi, encercant entre los llibres dels filòsofs e poetes alguna cosa $a b$ la qual pogués complaure a les dones virtuoses, ocorrec l'altre dia una història la qual recita Petrarca, poeta laure-

À mui honorável e honesta senhora madona Isabel de Guimerà, Bernat Metge, saúde e reverência.

$\mathrm{Eu}$, procurando entre os livros dos filósofos e poetas alguma coisa com a qual pudesse deleitar as mulheres virtuosas, encontrei noutro dia uma história recitada por Petrarca, poeta lau-

${ }^{10} \mathrm{O}$ asno de ouro ou as Metamorfoses é o único romance da literatura latina antiga que conservamos integramente. $\mathrm{O}$ escritor africano Lucius Apuleio narrou as aventuras de um homem que se vê transformado em asno por um encantamento e vivencia uma série de aventuras sob essa forma animal. Dentro da narração geral se contam várias histórias; a mais extensa conta os amores de Eros, o deus do amor, e bela princesa Psiquê. 
at, en les obres del qual jo he singular afecció. E con la dita història sia fundada en virtuts de pasciència, obediència e amor conjugal, e a mi sia cert que, entre les altres virtuts, vós, senyora, siats dotada d'aquestes singularment, per ço he delliberat d'arromançar la dita història, e de trametrela-us perquè vós e les altres dones virtuoses prenats eximpli de les coses en aquella contengudes, no per tant que jo em pens que vosaltres freiturets d'aquesta doctrina, car sens ella sóts assats pascients e virtuoses, mas per co que oints la present història, siats pus ardents en seguir les dites virtuts, car diu lo mestre d'amor, Ovidi, en les obres del qual en temps que jo amava me solia molt adelitar, que al cavall lleuger quan corre no li nou si hom li dóna alguna esperonada. Suplicantvos que la present història vullats benignament oir, en les adversitats, les quals algú en aquesta present vida no pot esquivar, com lloc serà, ben remembrar d'aquella, per ço que mills e pus pascientment puixats aquelles soferir, de les quals Déu vos vulla preservar per sa mercè.

\section{$\star \star \star$}

La present història, senyora molt graciosa, he arromançada com pus pla he poscut e sabut; la qual, en esgordament del llatí en què Petrarca la posà, és fort grossera. Mas jo, imaginant que complauria a vós, no he recusat reado, por cujas obras eu tenho singular afeição. E como a dita história está fundada em virtudes de paciência, obediência e amor conjugal, e sei como certo que, entre as outras virtudes, vós, senhora, sóis singularmente dotada delas, por isso decidi arromançar a dita história, e transmiti-la para que vós e as outras mulheres virtuosas tomeis exemplo das coisas que ela contém, não porque que eu pense que vossas mercês precisem dessa doutrina, pois sem ela são extremamente pacientes e virtuosas, mas porque, ouvindo a presente história, sejais mais ardentes em seguir as ditas virtudes, pois diz o mestre do amor, Ovídio, em cujas obras eu costumava me deleitar muito nos tempos em que eu amava, que ao cavalo ligeiro quando corre não lhe faz mal se se lhe dá alguma chicotada. Suplico-vos ouvirdes de bom grado a presente história, e, quando for o caso, nas adversidades que ninguém nesta vida pode evitar, vos lembrardes dela, para, assim, poderdes sofrê-las melhor e mais pacientemente, das quais queira Deus vos preservar pela sua mercê.

A presente história, senhora muito graciosa, arromancei como melhor pude e soube; a qual, despojada do latim em que Petrarca a verteu, é muito grosseira. Mas eu, imaginando que agradaria a vós, não recusei em de- de demostrar la mia grossera ineptitud e atreviment gran que he haüt com he gosat parlar aprés tan solemne poeta com aquell és, lo qual viurà perpetualment en lo món per fama e per los insignes llibres que ha fets a nostra instrucció, suplicant-vos, senyora, que la dita història vullats creure així com és posada, car així fo allà com dessús és dit, jatsia que alguns menyscreents e viciosos diguen que impossible és que dona del món pogués haver la pasciència e constància que de Griselda és escrita. Als quals hom poria ben respondre que ells tenen aquell opinió per ço com imaginen que açò qui a ells és difícil sia als altres impossible. Car moltes dones són estades qui han haüda meravellosa pasciència, constància e amor conjugal, així com fo Pòrcia, filla de Cató, qui es matà com sabé que Varró, marit seu, era mort, e Hipsicratea, regina, qui volc anar per lo món així com exellada ab Mitridates, marit seu, e moltes altres coses les quals de present no em cur de recitar.

Suplic-vos, encara, senyora que mi, per envejosos contra justícia maltractat, vullats haver per recomanat en vostres devotes oracions; car Nostre Senyor ha mes en vós tant de bé, e vós que en sabets tan virtuosament usar, que no em pens que denant Ell poguéssets trobar repulsa de res que li demanàssets. mostrar a minha grosseira inépcia e o grande atrevimento que tive quando ousei falar junto a tão solene poeta como ele é, o qual viverá perpetuamente no mundo pela fama e pelos insignes livros que fez para a nossa instrução, suplicando-vos, senhora, que em dita história queirais crer assim como está escrita, pois aconteceu assim como está dito acima, ainda que alguns viciosos e menos crentes digam que é impossível que uma mulher deste mundo pudesse ter a paciência constância que de Griselda está escrita. Aos quais poderia bem responder que eles têm essa opinião porque imaginam que isso que para eles é difíci seja para os outros impossível. Pois já houve muitas mulheres que tiveram paciência maravilhosa, constância e amor conjugal, assim como foi Pórcia, filha de Catão, quem se matou quando soube que Varrão, o seu marido, tinha morrido, e Hipsicratea, rainha, que quis ir pelo mundo assim exiliada com Mitrídates, seu marido, e muitas outras coisas as quais agora não me preocupo de recitar.

Suplico-vos, ainda, senhora, que, maltratado contra a justiça pelos invejosos, me queirais encomendar nas vossas devotas preces; pois Nosso Senhor colocou em vós tanto bem, e vós o sabeis tão virtuosamente usar que não creio que perante Ele pudésseis encontrar rechaço de nada que lhe pedísseis.

Scientia Traductionis, n.11, 2012 
O início da história de Griselda em italiano, latim, catalão, francês, espanhol e português: itinerários de ida e volta

Nosso objetivo é apresentar o conto de Griselda como um vetor na encruzilhada da tradução tardo-medieval e renascentista, em um momento em que as incipientes línguas romances competem com o latim como línguas nacionais e, portanto, como veículos adequados para a expressão literária. $\mathrm{O}$ termo tradução deve ser entendido aqui como uma imitatio que se serve de um texto fonte para desenvolver o relato. Assim, existem divergências notáveis entre as várias versões, tanto na extensão dos trechos quanto na organização do material narrativo. Em todo caso, nos parece que essa breve antologia traça um caminho de ida e volta. O romance nascia na França um par de séculos antes precisamente como traduções do latim para o vernáculo ${ }^{11}$. Boccaccio cria o Decameron já em toscano, em língua vulgar, mas Petrarca retorna a narração à tradição latina. Por conseguinte, a tarefa de Metge, de Mézières, e dos outros, é trazer de volta o conto para as línguas medievais e, de alguma maneira, para as culturas a que os personagens da Griselda pertenciam.

Nardone e Lamarque (2000) reuniram o texto integro de oito versões da novela. Aqui utilizamos essa fonte para reproduzir, nas línguas citadas, o início do conto: a descrição do ducado de Saluzzo e a exposição do problema inicial dos vassalos do duque Gualtieri que querem que ele case para garantir um herdeiro. Reproduzse o diálogo entre os vassalos e o duque, chegando, grosso modo, até a apresentação da personagem de Griselda como mulher virtuosa.

\footnotetext{
${ }^{11}$ Lembremo-nos de que romance ou romanço, românico, tem a mesma raiz de arromançar, aqui usado exclusivamente como tradução em língua românica.
} 
italiano -

Griselda

1350

Giovanni Boccaccio
Decameron $(\mathrm{X}, 10)$

Già è gran tempo, fu tra' marchesi di Saluzzo il maggior della casa un giovane chiamato Gualtieri, il quale, essendo senza moglie e senza figliuoli, in niuna altra cosa, il suo tempo spendeva che in uccellare e in cacciare, né di prender mogli né d'aver figliuoli alcun pensiero avea; di che egli era da reputar molto savio. latim -

\section{Griseldis}

1373

Francesco Petrarca Seni-

les (XVII,3)

st ad Italie latus

occiduum Vesullus ex

Apenini iugis mons unus

altissimus, qui, vertice

nubila superans, liquido

sese ingerit etheri, mons

suapte nobilis natura, Pad

ortu nobilissimus, qui eius

e latere fonte lapsus

exiguo, orientem contra

solem fertur, mirisque

mox tumidus incrementis

brevi spatio decurso, non

tantum maximorum unus

amnium sed fluviorum a

Virgilio rex dictus

Liguriam gurgite violentus

intersecat; dehinc Emiliam

atque Flaminiam

Venetiamque disterminans

multis ad ultimum et

ingentibus hostiis in

Adriacum mare descendit.

Ceterum pars illa terrarum

de qua primum dixi, que

et grata planitie et

\section{catalão - \\ 1388}

Bernat Metge

Valter e Griselda

En Itàlia és una província ornada de molts notables castells e viles, apellada lo Marquesat de Saluça, de la qual era marqués un fort noble baró apellat Valter, jove, bell e molt graciós, no menys noble de costums que de llinatge, e, finalment, en totes coses fort insigne; sinó que, content d'açò que fortuna li havia dat, no curava de l'esdevenidor e trobava tan gran pler en caçar que totes les altres coses que a fer havia ne menyspreava. E especialment no es curava de prendre muller, de la qual cosa los seus vassalls e sotmesos eren fort dolents e despagats. francês -

\section{Griseldis}

$\mathbf{1 3 8 4}$

Philippe de Mézières Le Miroir des Dames Ma-

\section{riées}

Es confines de pieumont en Lombardie, aussy comme au pié de la grant montaigne qui divise France et Ytalie, a une contrée longue et lée, qui est appellée ou pays mont Besée, et est tres bien habitée d'aucunes cités, chastiaux et villes en plain et en montaignes, aournée de bois, de pres et de rivieres, de vignes et de fruits et de terres ahannables, la qualle contrée et anciennement seignourie naturele, es tamps passés et aujourd'hui fu toujours gouvernée par les marquis de Saluce. Or est ainsi, selonc l'histoire, que jadis entre les marquis en ot un, appellé Gautier, seigner sans per de celle noble contrée, auquel tous les autres marquis de la espanhol -

\section{Grisélida \\ 1384}

Joan Timoneda

El Patrañuelo

Por su bondad, Grisélida fue marquesa; obedecía for

En los confines de Italia hacia el poniente, región

harto deleitable y poblad de villas y lugares, habitaba un excelente y famosísimo marques, que se decía Valtero, hombre de gentil y agradable disposición, y de grandes fuerzas, puesto en la flor de su mocedad, no menos noble en virtudes que en linaje. Era, finalmente, en todo muy acatado, salvo que contentándose con solo lo presente era en extremo descuidado en mirar por lo venidero; tanto, que toda su ocupación era correr monte, volar aves, que todo lo demás parecía tener puesto en olvido; y lo que sobre esto sentían sus vasallos, era que no curaba de casarse ni quería que le hablasen de ello. português -

\section{Grisélida}

1595

Gonçalo F. Trancoso

Contos e Histórias de

Proveito e Exemplo (V)

Em os confins de Itália, mais à parte do Poente,

região alegre e deleitosa, povoada de vilas e lugares, habitava um excelente e famosíssimo Marquês, que se chamava Valtero, homem mancebo dotado de grandes forças e rara gentileza, não menos nobre em virtudes que em que em linguagem; salvo que, contentando-se com só o presente, era em extremo descuidado no porvir, tanto que toda sua ocupação era correr mon-

tes, voar aves e outros exercícios de caça, de modo que tudo o demais tinha posto em esquecimento e, sobretudo, o mais que seus vassalos sentiam era que não curava de se casar nem queria que lhe falassem em tal 


interiectis collibus ac
montibus circumflexis,
aprica pariter ac iocunda
est, atque ab eorum quibus
subiacet pede montium
nomen tenet, et civitates
aliquot et opida habet
egregia. Inter cetera, ad
radicem Vesulli, terra
Salutiarum vicis et
castellis satis frequens,
marchionum arbitrio
nobilium quorundam
regitur virorum, quorum
unus primusque omnium
et maximus fuisse traditur
Valterius quidam, ad
quem familie ac terrarum
omnium regimen
pertineret; et hic quidem
forma virens atque etate,
nec minus moribus quam
sanguine nobilis, et ad
summam omni ex parte
vir insignis, nisi quod
presenti sua sorte
contentus, incuriosissimus
futurorum erat. Itaque
venatui aucupioque
deditus, sic illis incubuerat
ut alia pene cunta
negligeret; quodque in
primis egre populi
ferebant, ab ipsis quoque
coniugii consiliis
abhorreret.

dicte region, barons et

chevaliers, bourgois et es-

cuiers, marchans et labou-

reus naturelment

obeisoient. Le dit Gautier, marquis de Saluce, estoit biau de corps, fort et legier, noble de sang, riche d'avoir et de grant seignourie, plain de toutes bonnes meurs et parfaictement garnis de dons de nature, de fortune et de grace. Une chose avoit en lui, car il amoit fort soli-

tude et n'acontoit riens au tamps à venir et quant on lui parloit de mariage, il

n'en voloit ouir parole.

Toute sa vie estoit dediée en bois et en rivières, en chiens et en oisyaux, et du gouvernement de sa signourie paou se melloit, pour quoy ses barons et son peuple estoient en grant tristesce, et par (...) coisa, tão embebido andava em seus passatempos. 
La qual cosa a' suoi uomini non piacendo, piú volte il pregarono che moglie prendesse, acciò che egli senza erede né essi senza signor rimanessero, efferendosi di trovargliele tale e di sì fatto padre e madre discesa, che buona speranza se ne potrebbe avere ed esso contentarsene molto.
Id aliquandiu taciti cum tulissent, tandem catervatim illum adeunt quorum unus cui vel autoritas maior erat vel facundia maiorque cum suo duce familiaritas,

"Tua" inquit "humanitas, optime marchio, hanc nobis prestat audaciam, ut et tecum singuli quotiens res exposcit devota fidutia colloquamur, et nunc omnium tacitas voluntates mea vox tuis auribus invehat, non quod singulare aliquid habeam ad hanc rem, nisi quod tu me inter alios carum tibi multis indiciis comprobasti. Cum merito igitur tua nobis omnia placeant, semperque placuerint, ut felices nos tali domino iudicemus.

Unum est, quod si a te impetrari sinis teque nobis exorabilem prebes, plane

felicissimi finitimorum

omnium futuri simus: ut

coniugio scilicet animum
Los quals, com molt ho haguessin soferit, anaren ensems al dit Valter, e la u d'ells, lo qual era de major auctoritat, o per bell parlar o per major privadesa que havia ab lo dit Valter, dir així:

- Molt noble marqués, tua humanitat dóna a nós audàcia e gosar que, tota vegada que els fets ho requiren, ab devota confiança parlam ab tu, e que ara les voluntats que tots tenim secretes en los nostros coratges la mia veu notific a les tues orelles; no pas que jo haja algun interès singular en açò, mas per tal com tu, segons que per molts indicis e senyals has sovent provat, mostres e reputes que jo són a tu molt car dénant tots los altres. Com, doncs, totes les tues coses plàcien e hagen a nós tostemps plagut, per ço que puixam jutjar que siam benaventurats corn aital senyor havem, e serem molt pus benaventu-
Disimularon algún tiempo estas cosas, pero al fin, habiendo su acuerdo, vinieron en presencia de él, y uno que parecía tener más autoridad y era más privado suyo, en nombre de todos, le dijo:

- Vuestra humanidad, excelente señor, nos da osadía para que cada cual de nosotros en particular, cuando el caso lo requiere, os pueda muy abiertamente declarar su intención. Así que ella misma me da a mí al presente atrevimiento para declararos las voluntades secretas de estos vuestros y obedientes vasallos, no porque yo sea para esto más hábil ni tenga mayor autoridad, sino la que vos, señor, con vuestras grandes mercedes me habéis querido dar.

Como quiera, pues, señor, sola una cosa nos queda la cual, si tenéis por bien concedernos, seremos sin duda los más bien afortunados hombres que halla
Dissimularam os seus, por algum tempo, estas coisas. Porém, havendo conselho entre eles, foi acordado que um que elegeram de mais autoridade lhe fizesse a fala seguinte:

- Vossa prudência e humanidade, excelente senhor, nos dá ousadia para que qualquer de nós ou-

tros em particular, quando o caso o requer, vos possa declarar abertamente sua tenção, assim que esta mesma me dá a mim 0 presente atrevimento para declarar-vos as vontades secretas destes vossos obedientes vassalos. Como quer que todas vossas coisas, manhas e costumes sejam de tanto valor e a todos pareçam tão bem que nos temos por mui ditosos sermos vassalos de tal Príncipe, só uma coisa nos falta, para de todos ser o contentamento perfeito: é que, senhor, queirais casar-vos e pôr-vos debaixo 
applices, collumque non liberum modo sed imperiosum legitimo subicias iugo, idque quam primum facias. Volant enim dies rapidi, et quanquam florida sis etate, continue tamen hunc florem tacita senectus insequitur, morsque ipsa omni proxima est etati. Nulli muneris huius immunitas datur, eque omnibus moriendum est; utque id certum, sic illud ambiguum quando eveniat. Suscipe igitur, oramus, eorum preces qui nullum tuum imperium recusarent. Querende autem coniugis studium nobis linque, talem enim tibi procurabimus que te merito digna sit, et tam claris orta parentibus ut de ea spes optima sit habenda. Libera tuos omnes molesta

solicitudine, quesumus, ne siquid humanitus tibi

forsan accideret, tu sine

tuo successore abeas, ipsi sine votivo rectore

remaneant".

A' quali Gualtieri rispose: rats en l'esdevenidor que tots nostres veïns, suplicam-te humilment que

vulles pendre muller, e que açò vulles fer espatxadament, car los jorns se'n van e volen fort lleugerament. E jatsia que tu sies en la flor de ton jovent, emperò la vellesa ensegueix aquesta flor; la mort és proïsma a tota

edat: tothom egualment ha a morir, e l'hora és incerta. Plàcia't, doncs, que oges

les pregàries d'aquells qui no menysprearien los teus manaments, e comana a nós l'elecció de la muller; car nós la't procurarem tal que ella serà digna d'acostar-se a tu, e de tal llinatge que tots porem estar $a b$ bona esperança d'ella.

Deslliura'ns, doncs, d'aquesta trista ànsia en què som, per ço que, si Déu

disposava en altra manera de tu, no te n'anasses menys de lledesme successor e nós romanguéssem sens regidor algú.

Lladoncs, lo dit Valter, mogut per les piadoses pregàries dels seus, dix: se pudieren en nuestros tiempos, y es que queráis, señor, casaros y poneros bajo el yugo matrimonial. Por tanto, señor, os suplicamos admitáis nuestros ruegos, así cual nosotros estamos prontos a vuestros mandamientos. Sacadnos, señor, de este tan grande cuidado, porque si de vuestra vida ordena

Dios otra cosa, no muráis sin heredero, y nosotros sin el señor que de tan

buen linaje deseamos.

Moviose el ánimo del

Movido o ânimo do MarMarqués con estos ruegos, y dijo: do jugo matrimonial porque, se de vossa vida, Deus Nosso Senhor ordenar outra coisa, não fi-

quemos sem herdeiro que de tão boa linhagem desejamos.

Scientia Traductionis, n.11, 2012 
"Amici miei, voi mi strignete a quello che io del tutto aveva disposto di non far mai, connsiderando quanto grave cosa sia a poter trovare chi co' suoi costumi ben si convenga e quanto del contrario sia grande la copia, e come dura vita sia quella di colui che a donna non bene a sé conveniente s'abbatte. E il dire che voi vi crediata a' costumi de' padri e dell madri le figliuole cnoscere, donde argomentate di darlami tal che mi piacrerà, è una sciocchez$\mathrm{za}$, con ciò sia che o non sappia dove i padri possiate conoscere, né come segreti delle madri $\mathrm{d} i$ quelle; quantunque, pur conoscendoli, sieno spese volte le figliuole a' padri e alla madri dissimili. Ma poi che pure $n$ queste catene vi piace

d'annodarmi, e io voglio eser contento; e acciò che o non abbia da dolermi d'altrui che dime, se mal venisse fatto, io stesso ne voglio essere il trovatore affermandovi che, cui che io mi tolga, se da voi non fi come donna onorata, voi proverete con gran vo-
"Cogitis" inquit "me, amici, ad id quod michi in animum nunquam venit delectabar omnimoda libertate, que in coniugio rara est. Ceterum subiectorum michi voluntatibus me sponte subicio, et prudentie vestre fisus et fidei. Illam vobis quam offertis querende curam coniugis remitto, eamque humeris meis ipse subeo. Quid unius enim claritas confert alteri? Sepe filii dissimillimi sunt parentum. Quicquid in homine boni est, non ab alio quam a Deo est. Illi ego et status et matrimonii mei sortes, sperans de sua solita pietate,

commiserim; ipse mich inveniet quod quieti mee sit expediens ac saluti.

Itaque quando vobis ita placitum est, uxorem ducam: id vobis bona fide polliceor, vestrumque desiderium nec frustrabor equidem nec morabor. Unum vos michi versa vice promittite ac servate: ut quamcunque coniugem ipse delegero, eam vos summo honore ac veneratione prosequamini,
- Vosaltres, amics, me forçats de fer cosa que jamés no fo al meu cor. Jo m'adelitava que visqués en llibertat, la qual fort tard

és en matrirnoni. Per què, jo em sotmet de bon grat a la voluntat de vosaltres. $\mathrm{E}$ jatsia que jo confio de la vostra saviesa e fe, vull rellevar vosaltres del càrrec que volets pendre per mi, car jo mateix me'n vull haver l'afany de cercar-

la'm, com jo sia cert que la noblesa de la u no ennobleix l'altre a que moltes vegades los fills són dessemblants als pares. Tot lo bé qui és en la persona no li ve d'altre sinó de Déu, al qual jo coman mi e tots mos afers, esperant que

Ell m'hi trobarà cosa que serà expedient a repòs $\mathrm{e}$ salut mia. E pus vosaltres trobats pler que jo prena muller, promet-vos que jo compliré vostre desig en breu; però vull que em prometats que qualsevulla muller que jo prena, ab sobirana honor e reverència la tractets, e que entre vosaltres no haja algù qui en diga mal ne es clam de la mia elecció per mi faedora. Qualsevulla muller
- « (...) Je me delitoyé en liberté et en franche volenté, laquelle est paou trouvée en mariage, ce scevent bien ceulx qui

l'ont esprouvé. Toutefois, pour vostre amour, je me sousmés à vostre bon conseil et à vostre volenté.

Vraye est que mariage est une chose doubteuse, et maintefois les enfans au pere pas ne ressamblent, toutefois se aucun bien

vient à l'omme, tout vient de Dieu lassus, à lui je recommans le sort de mon mariage, esperant en sa doulce bonté qu'il m'octroyera telle avec laquelle je puisse vivre en pais et en repos expedient a mon salut. Je vous octroy, mes amis, de prendre femme et le vous promés, mais de vous je vueil une chose que vous me pomettés et gardés, c'est assavoir que celle que je prendray, par ma election, quelle qu'elle soit, fille du prince des Romains ou autre, vous le doyés entierement amer et honorer, et qu'il n'ait aucun de vous qui après de ma election du mariage doye estre mal content, jugier ne murmu-
- Forzáisme, amigos, a pensar en cosa muy ajena de mi pensamiento, porque holgaba vivir con entera libertad, la cual en los casados es muy rara. Pero yo quiero someterme a vuestras voluntades, con tal condición, que vosotros me prometáis y guardéis una cosa, y es que la que yo escogiese por mujer, sea quien fuere, con toda honra y reverencia sirváis, y que de mi elección en esta parte ninguno de vosotros en algún tiempo contienda o se queje: básteos que se conceda vuestra petición en casarme.
- Forçais-me, amigos, a cuidar em uma coisa mui alheia de meu pensamento, porque folgava vive em inteira liberdade que no estado dos casados se acha mui raras vezes. Porém, eu quero submeterme a vossas vontades, com tal condição que me prometais e guardeis uma coisa que vos quero pedi e é que a mulher que eu escolher, seja quem for, que vós outros a sirvais com toda honra e acatamento possível e que de minha eleição nenhum de vós outros se queixe em algum tempo. Baste que vos conceda o casar-me com muito prazer e contentamento. 
stro danno quanto grave mi sia l'aver contra mia voglia presa mogliere a' vostri prieghi."

I valenti uomini risponson ch'eran conttenti, sol che esso si recasse a prender moglie. nec sit ullus inter vos qui de meo unquam iudicio aut litiget aut queratur.

Vestrum fuerit me

omnium quos novissem

liberrimum iugo

subiecisse coniugii; mea

sit iugi ipsius electio;

quecunque uxor mea erit,

illa, ceu Romani principis

filia, domina vestra sit".

Promittunt unanimiter ac

lete nichil defuturum, ut

quibus vix possibile

videretur optatum diem

cernere nuptiarum, de

quibus in diem certum

magnificentissime

apparandis domini

iubentis edictum alacres

suscepere. Ita e colloquio

discessum est, et ipse

nichilominus eam ipsam

nuptiarum curam

domesticis suis imposuit, edixitque diem. que jo pendré, aquella vull rer. »

que sia vostra senyora, e

sia així tractada per vosal-

tres com si era filla de

l'emperador.

Lladoncs, tots a una veu, concordablement, li prometeren fort alegrement d'atendre e complir son manament, així com aquells qui per sobres de goig a penes cuidaven

veure lo dia de les nùpci-

es: ab tan gran goig e pler l'esperaven. Lo qual dia lo dit Valter los assignà que fossen aparellats a la celebració d'aquelles; e no-

res-menys manà als seus domèstics e familiars que solemnement aparellessin les coses necessàries a la festa.
Lors tous les barons, chevaliers et subgés du marquis presens, ayans ce qu'il demandoyent, de laquelle chose maintefois avoyent esté desesperéz, à une vois remercierent au marquis leur seigneur en promettant de bon cuer le pact et convenance qu'il leur avoit demandé. Grant joye ot ou palays de $\mathrm{Sa}$ luce et par le marquis fu le jour assené de ses noces auquel il devoit prendre femme et fu commandé de faire un grant appareil, trop plus grant que par autre marquis autre fois n'avoit esté fait et que les parens et amis voisins et les dames du pays haultement fussent semons à la dicte journée, laquelle chose fu solempnelment acomplye. Entre tant que
Con mucho gozo y concordia prometieron los vasallos de hacer lo que el marques les propuso, como hombres que apenas podiam creer que habían de ver el deseado día de estas bodas; las cuales él les declaró para día cierto porque se aparejasen a solemnizarlas con much magnificencia, para lo cual ellos se ofrecieron de muy amorosa gana. $\mathrm{Y}$ as se despidieron del Marqués con gran contentamiento.
Prometeram os vassalos de fazer tudo o que o

Marquês lhes pedia, como homens que não podiam crer que haviam de ver o desejado dia das suas bodas, as quais ele declarou para certo dia por que se aparelhassem para as solenizar com muita magnificência. Ao qual todos se ofereceram de mui inteira vontade e assim se despediram do Marquês com grande contentamento. 
Erano a Gualtieri buona pezza piaciuti i costumi d'una povera giovinetta che d'una villa vicina a casa sua era, e, parendogli bella assai, estimò che con costei dovesse aver vita assai consolata. E per ciò, senza più avanti cercare, costei propose di volere spoare: e fattosi il padre chiamare, con lui, che poverissimo era, si convenne di torla per moglie.

(...)
Fuit haud procul a palatio villula paucorum atque inopum incolarum, quorum uni omnium pauperrimo Ianicole nomen erat; sed ut pauperum quoque tuguria nonnunquam gratia celestis invisit, unica illi nata contigerat Griseldis nomine, forma corporis satis egregia, sed

pulcritudine morum atque animi adeo speciosa ut nichil supra. l'appareil se faisoit, le marquis de Saluce,

comme il avoit acoustumé, aloit en son deduit chassier et voler.

No molt lluny del palau del dit marqués era situada una vila petita, poblada d'alguns pagesos, fort pocs e pobres, entre els quals n'hi havia u pus pobre que tots apellat Janícola; e havia una filla apellada Griselda, assats bella de cors, e molt pus bella e noble de bones costumes e de virtut del coratge; la qual s'era nodrida en sobirana pobresa, ab vianda grossera, e, ignorant tot desig car-
Et assés pres du chastiau de Saluce avoit une povre villete, en laquelle demouroient un paou de laboureus, par laquelle villete ou hamiau le marquis souventefois passoit. Et entre les dessusdiz laboureux avoit un viel homme qui ne se pooit aider, povre et plain de toute miser, appellé Janicola. Et toutefois aucunefois es povres maisoncelles la grace de Dieu habite, car à
Idos, el Marqués, como al punto que le hablaron sus vasallos del casamiento le pasó por la memoria de los servicios y bondad y gentileza de Grisélida, sabia, graciosa pastora, que por diversas veces, yendo a caza, había recibido,

siendo hospedado en casa de su padre Janícola, rico cabañero, determinó que

Grisélida fuese su mujer, y por eso les señaló el día de las bodas, y por el consiguiente, a todos los criados y servidores de su casa.

Idos, o Marquês, como no ponto que lhe falaram seus vassalos no casamento, logo the passou pela memória a graça e gentileza de Grisélia, sábia e graciosa lavradora que por diversas vezes, indo à caça, havia visto, sendo hospedado em casa de seu pai Janícola, um rico lavrador. Determinou que Grisélia fosse sua mulher e, portanto, lhes assinou a seus vassalos o dia de suas bodas.

Grisélida, no lejos de ciudad a donde el Marqués tenía sus palacios, residía con su padre Janícula en un lugarejo de pocos y pobres moradores, con gran copia de ganados, que con la industria y sagacidad de ella eran regidos y gobernados, harto hermosa y de buen parecer cuando a la disposición y presencia. (...)
Morava Grisélia não longe da cidade onde o Marquês tinha seus paços, e com seu pai em um lugarzinho de poucos e pobres moradores, com algum gado que, com a indústria e sagacidade de Grisélia, eram governados e regidos grandemente. (...) 
nal, jamés no havia imaginat ne girat l'enteniment en folls ne en delicats pensaments, ans reposava en lo seu pit virginal coratge d'home vell e savi. (...) celui povre homme Janicola estoit demouré une fille appellé Griseldis, assés belle de corps, mais trop plus belle de l'ame et des bonnes meurs à Dieu en son degré, nouryé des tres petite vie et en tres grant povreté : et n'avoit pas aprins d'estre nourie de viandes delicieuses, ne choses riches, molles et delicatives jamais en sa pensée n'entroyent, mais un corage vertueux plain d'umilité et de toute meurté en son pis virginal doulcement habitoit (...) 


\section{Considerações finais}

Neste trabalho reconstruímos a gênese e a transmissão da história de Griselda e Gualtieri dentro de um contexto românico, no período da transição entre a Idade Média e o Humanismo. Boccaccio colocou esse conto popular (já que muito provavelmente tem raízes folclóricas) em um lugar privilegiado do Decameron, e a excelente tradução latina de Petrarca lhe outorgou uma imensa transcendência literária. Por outro lado, a versão latina de Petrarca opunha o latim, língua das universidades e da cultura, ao vulgar, ao vernáculo romance toscano, que, ao mesmo tempo, ele e Boccaccio - seguindo o rastro de Dante - ajudavam a afiançar como língua de criação literária e de cultura; em um momento em que as línguas vernáculas lutavam por se consolidar como idiomas autônomos.

Aqui prestamos particular atenção à versão que Bernat Metge fez ao catalão e observamos que essa foi a primeira tradução que se fez de uma das novelle do Decameron no âmbito ibérico. Expusemos as cartas que o tradutor barcelonês dirige a sua benfeitora e, do lado, colocamos nossa tradução ao português, disponibilizando assim as ideias que ele expõe ao público lusófono-brasileiro. Além disso, apresentamos as versões francesa, castelhana e portuguesa do...; consideramos que a variedade de estilos com que se transmite a história é boa prova das diferentes abordagens aplicadas pelos tradutores, o que corresponde bem ao conceito da imitatio. De maneira geral, constatamos que essas e outras traduções forneceram modelos literários sobre os quais as incipientes línguas neolatinas consolidaram os seus alicerces como veículos de expressão literária.

Os motivos que compõem o conto da paciente Griselda, a sua origem e difusão nas mais diversas línguas já foi argumento de inúmeros trabalhos ${ }^{12}$. e, desde aqui, acreditamos que esse tema não se esgota.

\section{Francisco Javier Calvo del Olmo} franciscoctl.ctl@gmail.com

Doutorando, Universidade Federal de Santa Catarina

\footnotetext{
${ }^{12}$ Cf. Rossi (1978), NANDORE E LAMARQUe (2000) e HANKIns (2008).
} 


\section{Referências bibliográficas}

BADIA, L. «Sobre la traducció catalana del Decameron de 1429», in Boletín de la Real Academia de Buenas Letras de Barcelona 1973-74, 35, pp. 69-101.

Boccaccio, Giovanni. Decameron. Nuova edizione riveduta e aggiornata. A cura di BRANCA, Vittore. Torino, Einaudi, 2 vols. 1992.

BRANCA, Vittore. «Intertestualità fra Petrarca e Boccaccio», in Lectura Petrarce, XIV. 1994, pp. 359-380.

Conde, Juan Carlos. «Un aspecto de la recepción del Decamerónen la Península Ibérica, a la sombra de Petrarca. La historia de Griselda», in Cuadernos de Filología Italiana UCM, $\mathrm{n}^{\circ}$ extraordinario 2001 pp. 351-371.

E-DICIONÁRIO DE TERMOS LITERÁRIOS http://www.edtl.com.pt/ , consultado em 06/05/2012.

Hankins, Jessica Lara Lawrence. Translations of Griselda. Saint Louis, Missouri: Washington University, 2008.

Metge, Bernat. Obras de Bernat Metge, ed. de RiQuer, M. de. Barcelona: Universitat de Barcelona, 1959.
NARDONE, Jean-Luque; LAMARQUE, Henri. L'histoire de Griselda, une femme exemplaire dans les lettres européennes. Tome 1: prose et poésie (Boccace, Pétrarque, Nerli, de Mezières, Metge, Timoneda, Trancoso, Deloney), Toulouse: Presses Universitaires du Mirail, 2000.

Petrarca, Francesco. De insigni obedientia et fide uxoria. Il Codice Riccardiano 991, Alessandria: Edizioni dell’Orso, 1998.

Romera CAStiLlo, José. "Bernat Metge y Joan Timoneda (patraña segunda): El doble filo de la imitatio: La Patraña Segunda de J. Timoneda", in eHumanista, 13, 2009, pp.210-218.

. «Ecos de la literatura medieval en El Patrañuelo», in Literatura Medieval. Actas do IV Congresso da Associação Hispânica de Literatura Medieval (Lisboa, 1-5 Outubro 1991), III. Nascimento, A. A. y Ribero, C. A. (eds.). Lisboa: Edições Cosmos, 1993, pp. 203-207.

Rossi, G. C. «Il Boccaccio nelle letterature in portoghese», in Il Boccaccio nelle culture e letterature nazionali. MAZzONI, F. (ed.). Firenze: Leo S. Olschki, 1978, pp. 223-237.

Tavani, Giuseppe. "De la Griseldis de Petrarca i la Griselda de Bernat Metge", in Els Marges, 16. 1979, pp. 99-104. 